\title{
Erratum: Slow-light-enhanced gain in active photonic crystal waveguides
}

Sara Ek, Per Lunnemann, Yaohui Chen, Elizaveta Semenova, Kresten Yvind \& Jesper Mork

Nature Communications 5:5039 doi: 10.1038/ncomms6039 (2014); Published 30 Sep 2014; Updated 30 Jan 2015

In Fig. $3 \mathrm{~b}, \mathrm{~d}$ and $\mathrm{f}$ of this Article, the $y$ axis label was inadvertently changed from $\mathrm{cm}^{-1}$ to $\mathrm{m}^{-1}$ during the production process. The correct version of Fig. 3 appears below.
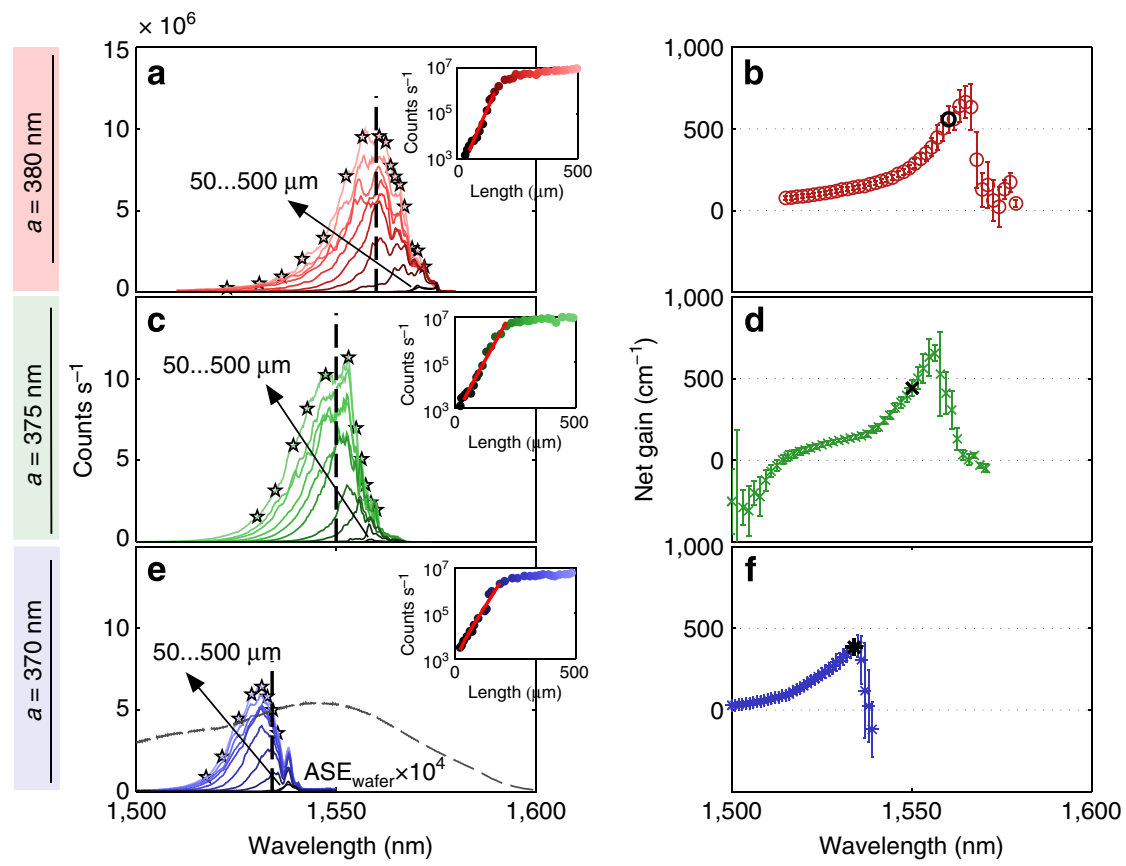

Figure 3 